\title{
Effect of feed space allowance on the performance of dairy cows offered grass silage based diets
}

\section{C.P. Ferris ${ }^{1}$, N. O'Connell ${ }^{2}$, D.C. Patterson ${ }^{1}$, D.J Kilpatrick ${ }^{1}$}

${ }^{1}$ Agri-Food and Biosciences Institute, Hillsborough, United Kingdom, ${ }^{2}$ Queens University of Befast, Belfast, United Kingdom

Email: conrad.ferris@afbini.gov.uk

Introduction Meeting the higher nutrient requirements of high yielding dairy cows remains a key challenge. While many studies have examined nutritional approaches to achieve increased food intakes, for example increasing the nutrient density of the diet, 'non nutritional strategies' may also have an important role in achieving higher intakes. As most food consumed by housed cows is consumed at a feed barrier, options for optimising the feed barrier environment is one of these 'non nutritional strategies'. This is particularly important at present in view of rapidly expanding herd sizes on many farms. As herds expand, some farmers continue to make use of existing feed barriers, thus reducing the feed space per cow, while others add additional barrier space at considerable cost. However, there does not appear to be an agreed 'optimum' space allowance per cow, with recommendations ranging from 20 to $100 \mathrm{~cm}$ per cow. If feed space is inadequate, this may have a detrimental effect on food intake, performance and welfare, and it might be expected that primiparous animals would be particularly affected. To address this issue, an experiment was undertaken to examine the effect of feed space allowance on the performance of dairy cows offered grass silage based diets.

Materials and methods Forty-two Holstein-Friesian dairy cows were allocated to one of three treatment groups (nine multiparous and five primiparous cows per group) at calving (mean calving date, 1 January). The three groups were housed in adjacent, but visually isolated pens of equal size and similar layout, with 16 cubicles per pen. Within each pen cows accessed food via a 'post and rail' type feed barrier. Treatments examined comprised three horizontal feed space allowances, namely 20,40 and $60 \mathrm{~cm} / \mathrm{cow}$. The experiment commenced with 14 late lactation non-experimental cows occupying each pen. Experimental cows were then transferred into the appropriate experimental pen within 36 hours of calving, and non-experimental cows removed, with the process repeated until each pen contained 14 experimental cows. Cows remained in their experimental groups for a mean of 127 days post-calving, with the period from the last cow calved until the end of the experiment being 88 days. Throughout the experiment cows had ad libitum access to a diet comprising grass silage and concentrates (65:35 DM ratio). Fresh food was offered at $10.30 \mathrm{~h}$ each day in the form of a mixed diet. Group intakes were recorded daily, but were not analysed statistically due to the unreplicated nature of the intake data. The effect of feed space allowance on mean animal performance during the experiment was analysed by ANOVA, with the individual cow used as the experimental unit.

Results Mean DM intakes with the 20, 40 and $60 \mathrm{~cm} / \mathrm{cow}$ treatments were 19.0, 18.7 and $19.3 \mathrm{~kg} / \mathrm{cow} / \mathrm{day}$. Feed space allowance had no significant effect on milk yield per cow, milk composition, milk somatic cell count, or on cow liveweight or condition score at the end of the experiment $(\mathrm{P}>0.05)$.

Table 1 Effect of feed barrier space allowance per cow on the performance of lactating dairy cows

\begin{tabular}{|c|c|c|c|c|c|}
\hline & \multicolumn{3}{|c|}{ Feed space allowance per cow } & \multirow[b]{2}{*}{ SEM } & \multirow[b]{2}{*}{ Sig } \\
\hline & $20 \mathrm{~cm}$ & $40 \mathrm{~cm}$ & $60 \mathrm{~cm}$ & & \\
\hline Total DM intake (kg/day & 19.0 & 18.7 & 19.3 & & \\
\hline Total milk output (kg/day $\dagger$ ) & 3820 & 2823 & 3705 & 164.4 & NS \\
\hline Milk yield (kg/day $\dagger$ ) & 32.2 & 31.5 & 31.0 & 1.89 & NS \\
\hline Milk fat $(\mathrm{g} / \mathrm{kg} \dagger)$ & 42.4 & 42.1 & 42.2 & 0.86 & NS \\
\hline Milk protein (g/kg†) & 31.3 & 31.2 & 32.3 & 0.46 & NS \\
\hline Milk lactose (g/kg $\dagger)$ & 48.6 & 48.2 & 48.8 & 0.39 & NS \\
\hline End of study condition score & 2.6 & 2.6 & 2.6 & 0.05 & NS \\
\hline End of study live weight $(\mathrm{kg})$ & 585 & 595 & 608 & 8.9 & NS \\
\hline
\end{tabular}

\$Final 88 days on experiment.

$\uparrow$ From calving until end of study

Conclusions The results of this experiment, in which food was offered ad libitum, provide no evidence that the feed space allowances examined had detrimental effect on any of the performance parameters measured. When examined purely from an animal production point of view, a space allowance of $20 \mathrm{~cm} / \mathrm{cow}$ would appear to be adequate. The number of cows/treatment was not sufficient to allow fertility performance to be examined. At a feed space allowance of $20 \mathrm{~cm}$ per cow, there were practical difficulties in being able to place the full allowance of food for a 24 hour period in front of the space available at the barrier.

Acknowledgement This study was co-sponsored by DARDNI and AgriSearch. 